MARKETING AND BRANDING
RESEARCH

\title{
The infrastructure attitude to strategic planning of information technology in organizations
}

\author{
Emad Rezaei ${ }^{1}$,Yazdan Rostami ${ }^{2 *}$, Maryam Ghafouri ${ }^{3}$, Atefeh Fashkhorani ${ }^{4}$, \\ MohammadAmin Ahmadi ${ }^{5}$ \\ ${ }^{1}$ Faculty Member, Accounting Department, Malayer Branch, Islamic Azad University, Malayer, Iran \\ 2,3,4,5 Master Student, Accounting Department, Malayer Branch, Islamic Azad University, Malayer, Iran
}

\begin{abstract}
Keywords:

Strategic Planning of IT, Organizational Architecture, ICT Master Plan

Correspondence:

Yazdanrostami11@yahoo.com

The strategic planning means the future planning of an organization; in other words, it refers to the direction that the organization wants to move in that direction. Strategic planning of the information technology for any organization is an evidence that the organization's information architecture in light of strategic considerations such as mission, objectives, and priorities of the organization becomes evident and it determines the necessary administration plan to achieve systems and forms the informational databases at the organizational level. To put differently, strategic planning of the information technology charter and the macro program in the field of information systems are generally considered as the information technology. Different approaches are used for planning. Now, the dominant approach for developing the long-term program or for ICT master plan of information technology is an approach of the organizational architecture or the information technology architecture. The purpose of this research is a preliminary introduction with an organizational architecture approach with the means of strategic planning of the information systems.
\end{abstract}

CAIMI Journals

\section{Introduction}

Although the information and communication technology (ICT) enhance the ability of human beings, however, such developments often by itself does not improve human life in many aspects. Mechanism and macro programs and specific strategies are required to achieve the certain purpose in the use of ICT. The most important program which is necessary to achieve these goals is the macro program or ICT master plan. 


\section{Strategic Planning}

Strategic planning is a continuous process of the systematic and risk-taking decisions with the greatest knowledge and awareness of future results that systematically organizes the efforts and attempts for undertaking these decisions which is needed and measures the results of these decisions against expectations through a systematic and organized feedback (Stueart, 1998). Strategic planning is a process in which the objectives, goals, and programs are designed and implemented. Of course, the regulated and implemented processes are both gradual and continual. The time scale for the strategic plans is about three years and will not take more than five years. Although long-term perspectives are considered in more general level but it should be flexible enough to respond to the changes. Strategic planning as a comprehensive planning and in its early form began in the 1960s. The primary and main purpose of the implementation of strategic planning was controlling the whole organization.

\section{Strategic Planning of Information Technology}

Strategic planning of the information technology for any organization is an evidence that the organization's information architecture in light of strategic considerations such as mission, objectives, and priorities of the organization becomes evident and it determines the necessary administration plan to achieve systems and forms the informational databases at the organizational level. To put differently, strategic planning of the information technology charter and the macro program in the field of information systems are generally considered as the information technology.

\section{Enterprise Architecture}

The term architecture creates a general meaning in our mind that is due to its history in the human civilization. More or less similar definitions are provided for this term in the organization bed and in the information technology. Perhaps architecture can be considered as the fundamental structure of systems, internal and external components and communication, and the principles governing designing and their development. Following this, the term enterprise refers to any set of organization that has common objectives and operations. This set can involve the whole organization, a distinct part in an organization, functional aspects of a system, or sometimes it can involve amidst organizational set.

Generally, the term of organizational architecture can be defined as an organizational plan that describes the structure of the mission, the needed information of the organization, and the necessary technologies for supporting them and explains the transition process to implement these technologies. In our intended definition in this research, the organizational architecture refers to the overall structure of the information technology planning systems which guides the optimal use of information technology to achieve business strategies (Perks \& Beveridge, 2003).

\section{Information Technology Planning and Informational Systems}

The organized planning refers to the infrastructure and to the needed organizational cart information system at all levels. The comprehensive planning in the organization specifies 
the needed infrastructure in all dimensions including technological, managerial, and human dimensions and accordingly, the organization's guidance focuses on the designing and implementation of different informational systems and the use of information technology tools. Getting into the strategic planning of information technology is a kind of management task and it focuses on a series of factors, namely the integration of information systems considerations in the organization's planning process; the planning for effective and longterm management and optimization of the information effects, information systems and information technology; the integration of all forms of manual and computer forms and communications; and the emphasis on the problems including the low knowledge of managers, communication barriers and problematic organizational approaches.

The information system planning is a managerial process to create information systems integration with the organization's planning process. In addition, it refers to relating the information system applications to the business objectives of the organization and to determining the essential information requirements to achieve long-term and short-term organizational goals.

The strategic planning of information technology is the first step of organizational architecture process such determining perspectives and mission goals, determining the strategic requirements, and providing strategic document of information technology. The purpose of strategic planning of information technology is creating alignment between the information technology applications and business strategies of the organization. The adaptation of organization's information technology planning to the organizational basic goals is one of the significant challenges in IT/ISP that the organization will be followed by an increase in productivity. Based on conducted studies, IT/ISP has been one of the most important issues of information technology managers and the organizations senior managers in recent years.

Three questions must be answered in the strategy formulation process:

1. How is the status of services related to the information technology of the organization at the present time?

2. How should be the status of such services?

3. What is the best way towards the desired position?

We should know for this purpose, what activities it is necessary to be done.

Knowing the activities for achieving these purposes is of great importance.

\section{The Achievements of Strategic Planning of Information Technology}

The most important achievements of the strategic planning of information technology include the saving in investment in the field of information technology and making it purposeful; providing an appropriate bed for implementation of integrated information systems; transformation and modernization of the available infrastructure of information technology to sync with the latest technologies; the issues that must be specified and examined in strategic planning of information systems; diagnosis of the existing intervals and gaps with the ideal architecture; identifying and evaluating the barriers; designing the options and the possible alternatives; comparative analysis of alternatives and choosing the premier option; developing a plan and implementing strategies of ICT; identifying the resources needed to 
achieve the desired situation; and the description and determination of prioritized projects and providing the necessary information for producing their RFP.

\section{The Approaches of the Information Strategic Planning}

The following information describes several approaches that focus on strategic planning:

\section{McFarlan and McCann Strategic Network}

Table 1 is similar to the networks that the Boston Consulting Group and General Electric had created and it is appropriate for selecting the communication strategy for the company. Four kinds of companies that the information technology has different strategic impact on them have been identified. These four categories are labeled as strategic, rotation, factory, and protection. Each of these four categories shows different organizational needs in information technology (Ward \& Peppark, 2002).

Table 1

Matrix of Strategic Information Technology

\begin{tabular}{ll}
\hline Strategic & Rotation \\
\hline $\begin{array}{l}\text { Strategy: Information Technology Guidance } \\
\text { The advantage is centrally planned }\end{array}$ & $\begin{array}{l}\text { Strategy: Information Technology } \\
\text { It is centrally planned } \\
\text { Centralized Governance or Free Market }\end{array}$ \\
$\begin{array}{l}\text { Strategy: Information Technology } \\
\begin{array}{l}\text { Members' scarce resource } \\
\text { Free Market }\end{array}\end{array}$ & $\begin{array}{l}\text { Strategy: Information Technology User } \\
\text { Essential Losses }\end{array}$ \\
Support & Scarce resource \\
\hline
\end{tabular}

\section{Parsons Linking Strategy}

One of the primary purposes of IS planning is to ensure the company needs for the information technology to be compatible with the firm framework for the management of the information technology. To emphasize on the importance of this compatibility, the companies should be aware of their linking strategy of the business program and information (Parsons, 1983).

Parsons (1983) proposed six general linking strategies that present a wide management framework to guide the use of the information technology in the company. Each of the six different strategy plans an approach that company can create the information technology objectives and policies, evaluate the projects, allocate the resources, and determine the performance standards.

The extent to which companies consciously selected each of these six strategies varies. Some companies have no clear strategy. In these companies with random strategy, the information technology applications companies are generally less successful in meeting the company needs and information technology and they have ineffective performance because senior managers, users and the internal department of IS have no common framework to practice. Parsons six strategies are central planning, advantage guidance, free market, monopoly, scarce resources, and necessary loss.

\section{The Critical Success Factors}


Rockart in 1979 began the development of a method to define the executive information needs. Critical success factors are the results of their efforts. This approach focuses on individual managers and their current information needs. Critical success factors can be used to help companies to identify information systems they need. For each executive manager, the critical success factors can be considered as some fields of help at work; so that these fields should move correctly to grow and improve the organization. Normally, there are less than 10 cases of these factors that every executive manager should consider. Moreover, in fact they are very dependent on time. The key fields should receive the identical attention and accuracy on behalf of the executive manager. Following this, most managers clearly have identified the critical factors.

Rockart (1979) found that there are four source for identifying of these factors: First source refers to an industry which involves a business within it. Every industry has critical success factors associated with every company in the industry. The second source is the company itself and its position becomes determined within the industry and most likely, the works of large companies predominated in an industry will provide one or more critical success factors for small companies in that industry. In addition, several companies may have the same factors but at the same time, they may have different priorities to those factors. The third source refers to the critical success factors of the environment such as the consumption trends, economy, and political factors in the country or countries in which the company operates. Fourth source tends to be the organizational fleeting factors; in other words, it refers to the company's areas of activities which are not at the center of attention while they need to be considered. In addition to these four sources, Rocart found two critical success factors. He named the first one as supervision and the second one as construction which mean maintaining ongoing operation and following the progress of the programs for change which was started by the executive manager, respectively. Rocart look at the success factors differently from one organization to another, from one period to another period, and from one manager to another manager.

\section{Business Systems Planning}

The other methodology applicable for planning is business systems planning that has been developed by IBM company. This approach is the most famous approach of planning. The main philosophy of the business systems is that it is the data of a company source. For this reason, the organization must be governed from a general point; so that it can best serve the goals of the organization and support its decision making activities. The institution data are the used word for complete set of company data. In practice, this word is used for those company data that can be computerized. As the administrative systems develop, the greater amount of an organization data will be computer-based.

The definition of these wide volumes of data is really difficult work, so that many organizations do not do a lot of effort in this case. The organizations that have attempted to define the institution data, most often used the business systems related to IBM company. The purpose of business systems is to discover fixed architecture information that supports all business processes. When the data needs of a business process such as shopping were identified, until the process remains unchanged, the information framework will remain 
constant. In addition, the business systems planning uses this information framework as a basis for future information systems planning.

\section{Nolan's Stages of Growth}

The stages of growth model of information technology in an organization (Figure 1) could be used as a framework for evaluating the characteristics of the information systems in the organization (Nolan, 1997). The main emphasis of Nolan is that IS department in a company passes through six stages of development. As the organization grows out of six stages, the ability of their systems and the methods for their controlling and understanding becomes more comprehensive and more advanced. The progress to the maturity stage allows the companies to make less effort to maintain the task of information systems and focus their efforts on the use of information technology to provide operational and strategic benefits (Ward \& Peppark, 2002). Figure 1 presents the Nolan's stages of growth.

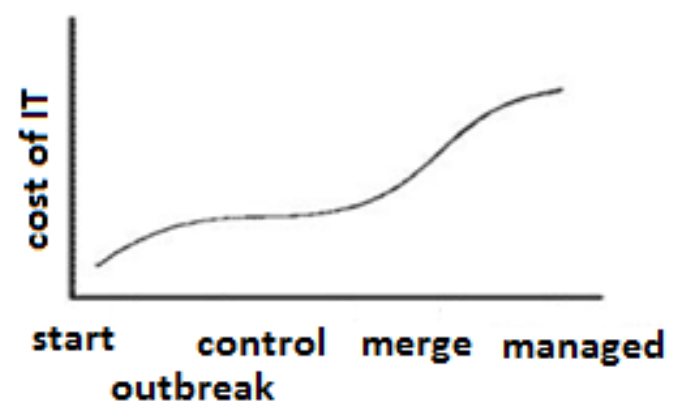

Figure 1. Nolan's stages of growth

\section{Investment Strategy Analysis}

Another framework to support the systems planning is based on some traditional techniques of portfolio planning and investment analysis. Kaplan and Norton (1996) described an approach that was used in a company to assist the customers in determining their investment strategies for information systems. They expected that four major types of information system applications to be used. These information system applications include common procedures of internal transaction processing as it is proposed in most of the modern data processing systems; the professional support systems including engineering support, management decision-making support, and similar activities; physical activities; and the systems that the users outside the company such as the customers and suppliers employ.

However, costs to provide a basic technical infrastructure to use and develop these applications will be developed. Telecommunications networks, standards of database, and other software of system are the main examples. To establish a framework for investment strategy a two dimensional table is set which have four types of system and infrastructure in columns and the rows contain the main functional components of trade, namely research and development, production, marketing, and other duties and functions related to services and supportive affaires.

Kaplan and Norton (1996) showed that there are significant differences in the ways companies invest in information systems. He stated that performing of such analysis helps to provide sufficient and appropriate reasons in the use of technology. This issue allows the 
managers to look from the distance to where that has been invested on and then to make decision that if they want to align investment of information systems with business strategy, where they should stand. Figure 2 shows the products and customers of information system.

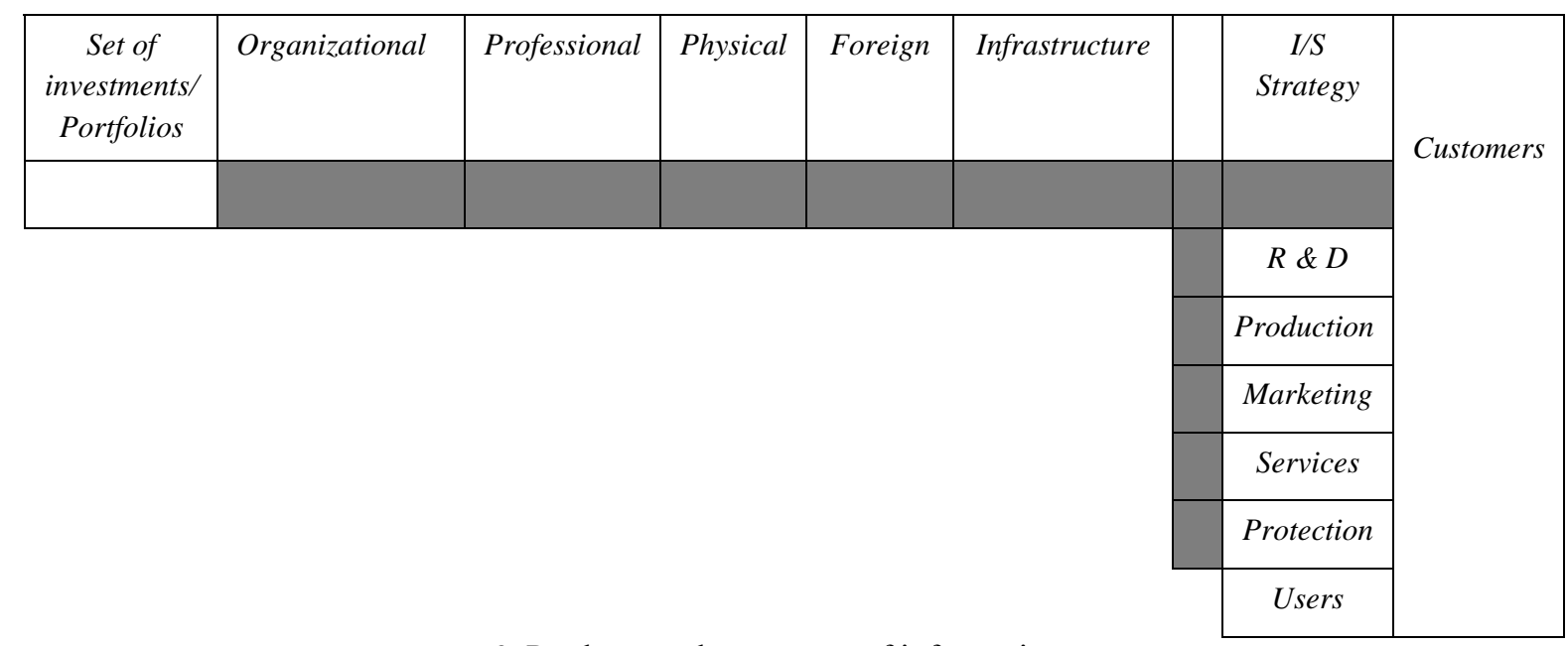

Figure 2. Products and customers of information system

\section{The Four-stage Model of EIT/ ISP}

The four-stage model of information technology planning is the infrastructure of developing the organization information systems portfolio which are properly aligned with organizational strategies and can create a competitive advantage for the organization. Competitive advantage involve creating a relationship between the strategic planning and information technology of the organization; understanding the systematic basic requirements of the organization to develop a strategic information architecture; the simultaneous allocation of development resources of information technology programs and the operational resources; and the designing of the executive program development of designed systems and allocation of necessary resources for development of these systems.

\section{The Existing Approaches for Macro Projects}

The existing approaches for macro projects contain the organizational management and planning; the information technology strategy of the organization; the comprehensive system of the organization; the management information systems; the enterprise architecture; reengineering; the comprehensive plan of the organization; and the information technology architecture of the organization.

\section{The Enterprise Architecture Approach for the Development of ICT Macro Program}

According to Zachman (1997), the theorist in the field of enterprise architecture has provided the necessity for changes in having updated quality orientation and acceleration of changes which forces us to turn to the enterprise architecture. In the $21^{\text {st }}$ century, the architecture is the determining factor in the success or failure of survival or ruin of the organizations. The 
US Congress passed signed a law in 1996 that became famous as Clinger-Cohen act. According to this law, all ministries and US federal agencies were required to adjust their information technology architecture. In accordance with this act, the chief information officer of any organization had control over the responsibility for the development, improvement, and the implementation of integrated information technology architecture. According to Clinger-Cohen act, information technology architecture is an integrated framework for the promotion and maintenance of existing technology and acquiring of new information technology to achieve the strategic goals of the organization and management of its resources. Following the adoption of Clinger-Cohen act that it is the most important legal document about the requirements of information architecture in the public organizations of US, the American management and budgeting organization published guidelines in 1996 on the necessity of coordinating of plans and conducted costs by American federal enterprises including ministries, agencies, military forces, and universities that take advantage of public funds; also, they have done the projects for planning and designing of their information architecture. Clearly, the benefits and advantages of an enterprise architecture approach can be grouped into two general categories, namely the general interests associated with the organization's business and related interests in information technology section and information systems and information technology supported business resources.

The enterprise architecture defines the future of organization in the fields of business, programs, information, and technology. In addition, it is the technical maps for complete and legal definition of the current situation (baseline) of the organization and the ideal environment and it is a bridge between organization strategies and their implementation.

Following this, the enterprise architecture is a macro attitude towards the organizational missions and tasks, business processes, information availabilities, communication networks, hierarchy and order of doing things in an organization with the aim of creating an integrated and efficient information systems.

The aim of designing enterprise architecture is to provide a working program in the information architecture layer, applications architecture, and technology architecture and the design of enterprise architecture refers to the process of defining the architecture layers to provide the needed information of the organization and designing of a plan to implement the architecture layers.

What are the hidden driving forces in enterprise architecture? The need for change is the most urgent need of the organizations and enterprise architecture is considered as the change tool. Over the last decade, the environments and information technologies are changing at a dramatic speed. In other words, new information technologies get old fast and organizations to keep up with the latest technology are continuously forced to incur substantial costs.

The budget and financial resources constraints make the organizations to act carefully in the field of investment on information technology and solid economic reasons and justifications for costs are required. Moreover, the need to identify the current situation, the desired position, and the desired direction is among hidden driving forces.

\section{The Main Objectives of the Enterprise Architecture}


The main objectives of the enterprise architecture include the transformation of the information technology from the tools mode to one of the organization resources and in service of the organization missions; providing the information technology strategic plan, the preparation of the existing situation of architecture and the desired conditions of the architecture, providing the appropriate transition plan from the existing situation to the desired one and updating the architecture; and the designing and implementation of information technology and the effective use of information and information technology by creating a relationship between the organization information and the future processes in the organization.

In addition, the enterprise architecture has some advantages. It leads to the collaboration between information technology and business processes; it ensures that information technology directly supports the strategic objectives; it causes the use of emerging technologies; it improves the purchase process in the field of information technology; it reduces the promotion costs, the information technology support costs, and the long-term maintenance costs; and it helps the consensus of the other business units of the organization in the field of information technology activities.

Following this, facilitating the change management, enhancing data sharing, reducing data redundancy and the software development cycle time, re-engineering of programs, realization of the investments benefits, and the reduction of the damages due to key employees leave are other advantages of enterprise architecture and most importantly, it completes the organization structure.

\section{Pyramid of Enterprise Architecture}

For ease of holistic in understanding the scope of information technology and the recreation of the organization based on information technology, the enterprise architecture approach follows mainly follows the information technology architecture pyramid model provided by the National Institute of US Technology Standards.

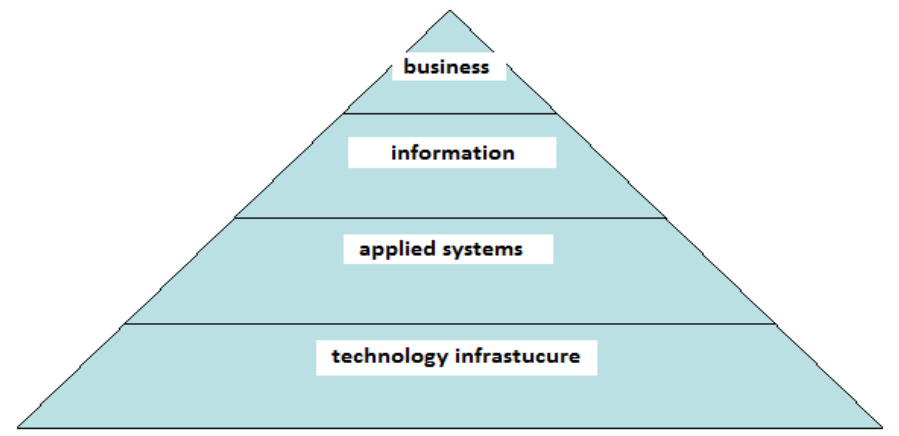

Figure 3. Pyramid of information architecture or enterprise architecture

Figure 3 represents the layers of planning and deployment of information technology within an organization that it is called as the enterprise information architecture pyramid and in short it is named as the enterprise architecture. As it can be seen, for enterprise architecture based on information technology a layered approach has been applied that from the bottom to 
the up of the pyramid each layer tends to act as a bed for its upper layer and also, the plan for its implementation is done from top to bottom.

In addition, this pyramid shows that the enterprise architecture based on information technology requires the participation of all strategic and operational levels in the architecture process that this path is obvious in the pyramid. This consideration imply that from the top levels to the bottom the strategic nature approaches the operational levels and that is why this technology affects all organizational levels and it is present in decision makings of these levels.

In fact, today, information is known as a strategic resource along with the other organizational resources such as financial resources, human resources, and equipment and technology. Thus, the technologies related to the preparation and use of information has strategic importance for organizations. However, for a better understanding of the enterprise architecture approach, it is better to look more accurately to the enterprise architecture pyramid. Therefore, we briefly examine the various layers from top to bottom.

Business Layer: The tip of the information technology architecture pyramid describes the aspects related to the organization business and trade. A series of activities including the issues such as business strategies, organizational technology, policies, and the scope and decision making about the information technology business paradigms like the electronic business should be done at this level. Also, in this layer, the issues such as the organizational structure of the business processes, planning and control systems as well as the administrative and managerial mechanisms for achieving the strategies and organizational goals are described and the relationship between them are modeled.

Information Layer: With the advent of computer systems and the expansion of their use in organizations, over time, it became clear that the mechanization of processes and operations does not guarantee their accuracy and efficiency. In other words, if the process be imperfect and non-optimal, its mechanization only will lead to the acceleration of wrong completion of a task. Therefore, for optimal use of information technology, the required information during the process of the organization must be optimized and modeled. Then, they become determined based on the clustering of information and the relationship of informational groups with the working process of required systems. In this layer, issues such as business process reengineering to improve and optimize the workflow and information are discussed. The needed basic information to perform organizational tasks is identified in information architectural layers.

The main needed information to perform organizational tasks is identified in the information architecture layer. Moreover, in this layer, the logical models of data categories and its relationships with the organization tasks and the systems of applications becomes identified. First, the subject areas of the organization are identified and classified and through of it, the information model is provided. In addition, logical databases and relationship between the subject areas and organizational tasks can be modeled in the form of different diagrams. Also, the issues such as the mechanisms and the knowledge management procedures are presented in this layer. 
Application Layer: This layer includes application systems which are necessary to achieve the defined functions in the upper layers. The systems such as enterprise resource planning, customer relationship management, management information systems, and supply chain management systems are included in this chain. The identification and description of the applications and modules and their relationship with the organization's processes and other applications is performed in the architectural application layer. The relationships between applications with the organizational tasks as well as with the functional areas of the organization are the other items that should be considered in designing of this layer of the architecture.

Technology or Infrastructure Area: In fact, this layer is the physical body of information technology. In other words, it refers to the thing that information technology is perceived in the minds of the public. This level of information technology includes of the hardware and software technologies such as microprocessors, personal computers, computer networks, telecommunications and electronic infrastructure, and software frameworks. In fact, the establishment of the organization's information systems is performed in this layer. In the architecture layer of infrastructure, the hardware and software technologies and the required telecommunications networks for the deployment of the application systems are identified and explained.

Technological needs of the organization become categorized based on four main technological areas, namely data management platform, operating systems, hardware processing, telecommunication technologies, and middle wares. However, what is seen in the first stage of information technology is its technological aspects that excessive fascination to this layer is a mirage that attracted the attention of many organizations and made them unaware of the understanding of the philosophy and principles of the information technology applications. There are many organizations that are equipped with the latest model of computing technologies but they could absorb the lowest percentage of its benefits.

\section{Developing the Enterprise Architecture}

The architecture process consists of three main phases in information technology strategic planning and planning enterprise architecture. The information technology strategic planning phase includes setting perspective, mission objectives, comparative study, determining the strategic requirements, and preparing the master plan document. The enterprise architecture planning phase contain attracting the attention of top management, managerial organization, defining the enterprise architecture process, creating the existing ideal situation of architecture, creating the transition plans, and defining the updating process of architecture. The enterprise architecture implementation phase involve the finalization of the ideal situation of the architecture, finalization of the transition plans, implementation of enterprise architecture, and evaluation and updating of enterprise architecture and transition plans.

\section{The Implementation Stages of Enterprise Architecture}


The implementation stages of enterprise architecture involve explaining the key features of the organization, describing the current state of organization from the point of view of information technology, determining the ideal situation of the organization considering the view of information technology in accordance with a specific planning horizon, and formulating the programs and needed strategies to move from the current situation to the desired situation.

\section{Conclusion}

A comprehensive information system program is essential for the development and successful application of information systems in organizations. The strategic and macro technologic planning prevents wasting the continued investments that inevitably occurs over many years in the field of information technology and uses these investments in the targeted form for the macro and strategic plans of the organization. For this, the information system planning process should be an integral part of the organizational overall efforts. In this research, some of the most popular approaches for information systems planning were described at strategic level. This highlights that no single method is the best and none of them is the most common method used in business. In fact, many companies take benefit from a combination of these approaches because they deal with various aspects of planning. Enterprise architecture is a new approach in which all activities and its supporting technologies are developed in the form pyramid, hierarchical form, and in the business intelligence application system and infrastructure. This approach acts far beyond the methodology of creating information systems and its scope encompasses the general information sources and organization's business processes. This approach has been used in large organizations with legacy systems which attempted to organize all the information resources of the organization in line with the business strategies and commercial purposes of the firm. The importance of information technology applications in the modern era and the features and benefits of enterprise architecture promises the broader and more inclusive vision of this approach.

\section{References}

Kaplan, R. S., \& Norton, D. P. (1996). The balanced scorecard: Translating strategy into action. Boston: Harvard Business School Press.

Nolan, R. L. (1979). Managing the crisis in data processing. Harvard Business Review, 57(1), 115-126.

Parsons, G. L. (1983). Fitting information system technology to the corporate needs: The linking strategy. Boston, Massachusetts: Harvard Business School Case Note.

Perks, C., \& Beveridge, T. (2003). Guide to enterprise it architecture. New York: Springer.

Rockart, J. F. (1979). Chief executives define their own data needs. Harvard Business Review, 57(2), 81-92.

Stueart, Robert D. (1998). Library and information center management ( $5^{\text {th }}$ ed.). Endewood, Colorado: Libraries Unlimited. Ward, J., \& Peppark J. (2002). Strategic planning for information systems (3 $3^{\text {rd }}$ ed.). Joun Wiley \& Sons.

Zachman, J. A. (1997). Enterprise architecture: The issue of century. Database Programming \& Design, 10(3), 44-53. 